\title{
Initial Transient in Zn-doped InSb Grown in Microgravity
}

\author{
A. G. Ostrogorsky, C. Marin, M. Volz*, T. Duffar** \\ Rensselaer Polytechnic Institute, Troy, NY, \\ *NASA Marshall Space Flight Center EM30, Huntsville, AL, \\ **SIMAP-EPM, BP 75, F-38402 Saint Martin d'Hères, France
}

Abstract

Three $\mathrm{Zn}$-doped InSb crystals were directionally solidified under microgravity conditions at the International Space Station (ISS) Alpha. The distribution of the $\mathrm{Zn}$ was measured using SIMS. A short diffusion-controlled transient, typical for systems with $\mathrm{k}>1$ was demonstrated. Static pressure of $\sim 4000 \mathrm{~N} / \mathrm{m}^{2}$ was imposed on the melt, to prevent bubble formation and dewetting. Still, partial de-wetting has occurred in one experiment, and apparently has disturbed the diffusive transport of $\mathrm{Zn}$ in the melt.

PACS: $81.05 . \mathrm{Ea} ; 81.10 . \mathrm{Fq} ;$ 64.70.Dv

Keywords: Directional Solidification, Segregation, de-wetting, Microgravity conditions, Semiconducting III-V materials.

\section{Introduction}

The diffusion-controlled segregation in microgravity [1] can be disturbed by the residual micro acceleration [2], or bubbles [3, 4]. Free surfaces and bubbles create a major disruption in fluid properties (e.g. density, conductivity) and boundary conditions. In such cases, the no-slip condition (i.e. zero melt velocity) at the container walls is suddenly replaced by a free surface which can move when exposed to surface tension gradients or residual micro-acceleration. Models of thermocapillary convection driven by voids during directional solidification [5] show that, in microgravity, void-generated thermocapillary convection is dominating the axial and radial segregation.

During crystal growth without melt convection, the impurities are transported by diffusion. Assuming uniform initial dopant concentration $\mathrm{C}_{0}$ in the melt, and constant growth rate $\mathrm{R}[\mathrm{cm} / \mathrm{s}]$, the distribution of the dopant in the crystal $\mathrm{C}_{\mathrm{S}}(\mathrm{x})$ can be calculated from the exact analytical solution derived by Smith et al. in 1955 [6], 


$$
\frac{C_{S}(\chi, k)}{C_{0}}=\frac{1}{2}\left\{1+\operatorname{erf} \sqrt{\chi}+(2 k-1) \mathrm{e}^{-4 \mathrm{k}(1-\mathrm{k}) \chi} \operatorname{erfc}[(2 k-1) \sqrt{\chi}]\right\}
$$

where the dimensionless concentration $C_{S}(\chi, k) / C_{0}$ is a function of the equilibrium segregation coefficient $\mathrm{k}$ and the dimensionless distance $\chi$,

$$
\chi=\frac{x}{L} \equiv \frac{x R}{4 D}
$$

where $L[\mathrm{~cm}]$ is the characteristic length, $\mathrm{R}[\mathrm{cm} / \mathrm{s}]$ is the growth rate, $\mathrm{D}\left[\mathrm{cm}^{2} / \mathrm{s}\right]$ is the diffusion coefficient of the dopant and $\mathrm{x}[\mathrm{cm}]$ is axial distance from the seed.

The crystal growth experiments conducted under microgravity conditions in the past 40 years reveal that the value of the equilibrium segregation coefficient $\mathrm{k}$ has a profound effect on the segregation behavior in microgravity. The first growth of $\mathrm{InSb}$ in microgravity was carried out by Witt et al. [1] in 1975. The experiments included growth of undoped, Te-doped $(k=0.5)$ and Sn-doped InSb (k=0.057). Zemskov et al. [7-9] grew Te- doped and Zn-doped InSb. The segregation profiles of $\mathrm{Zn}$-doped InSb were not reported.

In 1987 Duffar et al. [5] investigated the growth of Sn-doped InSb, using a calorimetric method proposed by the authors. The segregation was considerably disturbed by a bubble which apparently caused Marangoni convection in the melt. Note again that $\mathrm{Sn}$ has a low segregation coefficient, $k=0.057$, so that diffusion controlled steady state segregation requires an extensive solute build up at the interface, up to $1 / 0.057=17.5 C_{0}$.

Segregation of systems with $\mathrm{k}>1$ was rarely studied in microgravity. Gillies et al. [10] investigated growth of $\mathrm{HgTe}-\mathrm{CdTe}$ having $\mathrm{k}=3.9$. To avoid interface breakdown due to constitutional supercooling, the growth rate was $0.2 \mu \mathrm{m} / \mathrm{s}(0.72 \mathrm{~mm} / \mathrm{hr})$. Although the level of the residual acceleration was less than $10^{-6} g_{0}$, large axial and radial variations of the composition were observed and attributed to convection driven by the residual micro acceleration. A relatively short initial transient was obtained, considering the low growth rate.

In 2002, seven InSb crystals were grown at the International Space Station (ISS), as a part of the SUBSA (Solidification Using a Baffle in Sealed Ampoules) investigation [11,12]. 
Indium Antimonide was chosen because of its low melting point $\left(525^{\circ} \mathrm{C}\right)$, which made the experiments suitable for the Microgravity Science Glovebox (MSG) facility at the ISS. The four Te-doped InSb crystals had a nearly identical diffusion controlled initial transient [10]. The equilibrium segregation coefficient of $\mathrm{Te}$ in $\mathrm{InSb}$ is $\mathrm{k}=0.5$. Since $(2 \mathrm{k}-1)=0$, equation (1) is reduced to [11],

$$
\frac{C_{S}(\chi)}{C_{0}}=\frac{1}{2}\{1+e r f \sqrt{\chi}\}
$$

Fig. 1 shows Eq. (1) plotted as a function of $\chi$ and k. Taking $C_{S}(\chi) / C_{0}=\phi(\chi)=0.95$ as the end of the transient, one gets the corresponding dimensionless length $\chi=1.45$ which was in agreement with the experimental results (for Te-doped InSb).

Here we present the results obtained with the three $\mathrm{Zn}$-doped InSb crystals and labeled SUBSA 08, 09 and 10.

\section{Length of the Initial Transient for systems with $k>1$}

Zinc was selected as dopant, because its equilibrium segregation coefficient is larger than one $(\mathrm{k}=2.9)$. Equation (1) can be written as,

$$
\frac{C_{S}(\chi)}{C_{0}}=\phi(\chi)+F(k, \chi)
$$

where,

$$
\phi(\chi)=\frac{1}{2}(1+\operatorname{erf} \sqrt{\chi})
$$

and

$$
F(k, \chi)=\left(k-\frac{1}{2}\right) \mathrm{e}^{-4 \mathrm{k}(1-\mathrm{k}) \chi} \operatorname{erfc}[(2 k-1) \sqrt{\chi}] .
$$

As noted earlier, for $\mathrm{k}=0.5, F(k, \chi)=0$. Given the precision of the resolution of the data available, $C_{S}(\chi) / C_{0}=\phi(\chi)=0.95$ giving $\chi \approx 1.45$ as the dimensionless length of the initial transient. For $k \neq 0.5$, one can identify the following two regions:

i. $\quad 0<\mathrm{k}<0.5, F(k, \chi)$ is negative, prolonging the transient.

ii. $\quad 0.5<k<\infty, F(k, \chi)$ is positive, shortening the transients. 
Therefore, all systems with $\mathrm{k}>0.5$, have a shorter diffusion controlled transient than that given by Eq. (2). For large $z$, the asymptotic expansion of the complementary error function is [13]

$$
\operatorname{erfc}(z)=\frac{e^{-z^{2}}}{\sqrt{\pi}}\left(\frac{1}{z}-\frac{1}{2 ! z^{3}}+\frac{1}{3 ! z^{5}}-\ldots\right) \approx \frac{e^{-z^{2}}}{\sqrt{\pi} z}
$$

Using $z=(2 k-1) \sqrt{\chi}$,

$$
\operatorname{erfc}[(2 k-1) \sqrt{\chi}] \approx \frac{e^{-(2 k-1)^{2} \chi}}{\sqrt{\pi}}\left(\frac{1}{(2 k-1) \sqrt{\chi}}\right)
$$

Eq. (1) is reduced to [14],

$$
\frac{C_{S}(\chi)}{C_{0}}=\frac{1}{2}\left\{1+\operatorname{erf} \sqrt{\chi}+\frac{e^{-\chi}}{\sqrt{\pi \chi}}\right\}
$$

Eq. (4) is valid for large $(2 k-1) \sqrt{\chi}$. One can see from Fig. 1 that, for $\mathrm{k}=2.9$ and $\chi>1$, Eq.(1) and Eq.(4) yield a nearly identical result (i.e. Eq. (4) should be used for $(2 k-1) \sqrt{\chi}>5$ ).

For $2.9<k<\infty$, the location $\chi \approx 0.7$ gives $C_{S}(\chi) / C_{0}=0.95$, which can be taken as the end of the initial transient and beginning of the uniform steady state segregation. Based on the above analysis, $\mathrm{Zn}$-doped $\mathrm{InSb}$ is a suitable dopant for diffusion-controlled growth in microgravity, expected to yield a short initial transient followed by steady state.

\section{Experimental Procedure}

The special furnace with a transparent gradient section and a video camera were located in the Microgravity Science Glovebox of the ISS [11,12]. This setup provided a side view to the SUBSA ampoule made out of fused silica (Fig. 2 a). Hence we were able to observe one side of the seed and the charge and make temperature adjustments during the seeding process, as needed. In the SUBSA 08 and SUBSA 09 experiments, $2 \mathrm{~mm} \pm 0.1 \mathrm{~mm}$ of undoped seed was melted as planned.

The crystals were grown by lowering the furnace temperature. During SUBSA 08 and SUBSA 09 , the cooling rate was $45{ }^{\circ} \mathrm{C} / \mathrm{hr}$, corresponding to a growth rate of $5 \mathrm{~mm} / \mathrm{hr}(1.389$ $\mu \mathrm{m} / \mathrm{s})$. However, in the SUBSA 10 experiment, due a software problem, the cooling rate was 30 ${ }^{\circ} \mathrm{C} / \mathrm{hr}$ corresponding to a growth rate of $3.334 \mathrm{~mm} / \mathrm{hr}(0.9259 \mu \mathrm{m} / \mathrm{s})$. Furthermore, the 
temperature could not be sufficiently increased, so that only $\sim 0.1 \mathrm{~mm}$ of the seed was melted.

To prevent dewetting, the melt was pressurized using a carbon piston driven by a carbon spring (Fig. 2b), providing $\sim 30 \mathrm{mmHg}\left(\sim 4000 \mathrm{~N} / \mathrm{m}^{2}\right)$ of static pressure in the melt. All carbon parts including springs were produced by the Energy Science Laboratories, Inc. To reduce friction between the moving parts, the graphite was polished and CVD coated with a $2 \mu \mathrm{m}$ thick layer of hard pyrocarbon, Fig. 2c). In SUBSA 08 and 09, a carbon baffle was used [12] to minimize the possible effects of residual micro-acceleration. The undoped seed crystals were prepared by W.A. Bonner of Cristallod Inc. using the vertical Bridgman process [11]. The doped charge was prepared by directional solidification in a multizone Mellen furnace at Rensselaer Polytechnic Institute, using $6 \mathrm{~N}$ In, Sb and $\mathrm{Zn}$.

\section{Results}

The SUBSA ampoules, containing the crystals grown in space, were cut open using a diamond saw. In all SUBSA ampoules, the saw dust (silica particles) was pulled into the ampoules, demonstrating that vacuum in the ampoules was not compromised during processing in microgravity or afterwards. All crystals slid out from the quartz ampoules under slight tapping, there was no need to section or etch the ampoules. All graphite parts, including the carbon springs, were shiny and did not exhibit any signs of surface contamination, e.g. due to vapor condensation. Although InSb expands by about $12 \%$ upon freezing, we did not observe any mechanical damage in the ampoule components.

In SUBSA 10, about $10 \%$ of the seed cross section was attached to the charge, demonstrating that seeding did occur. Approximately $100 \mu \mathrm{m}$ of the seed were melted.

To measure the axial distribution of $\mathrm{Zn}, 1 \mathrm{~mm}$ thick plates were cut from the central section of the crystals (Fig. 3 b) using a diamond impregnated wire saw (South Bay Technology, Model 850), and polished using subsequently 1,200 grit paper, $10 \mu \mathrm{m}$ diamond particles and 1 $\mu m$ silica particles. At Charles Evans \& Associates, Sunnyvale, CA, SIMS measurements were conducted along the centerline of these plates.

The distribution of $\mathrm{Zn}$ is shown in Figs. 4 to 6. SUBSA 08, 09 and 10 were each doped with $0.0009 \pm 0.00005 \mathrm{~g}$ of $\mathrm{Zn}$. For SUBSA 10, the initial $\mathrm{Zn}$ concentration, determined from the weight of $\mathrm{Zn}$ added to the melt, was $C_{0}=2.1 \cdot 10^{18} \mathrm{~cm}^{-3}$. Two sets of SIMS data were taken, 
because the fist set of data (SIMS_1 in Fig. 4) had 21 out of 24 points above $C_{0}=2.1 \cdot 10^{18} \mathrm{~cm}^{-3}$. However, the second set of SIMS data (SIMS_2, Fig.4) taken on the next day, gave consistent values of $\mathrm{Zn}$ distribution. The average $\mathrm{Zn}$ concentration in the crystal can be calculated from the SIMS data as,

$$
C_{0, \text { SIMS }}=\frac{1}{L} \int_{0}^{L} C(x) d x \approx \frac{1}{L}\left\{\sum_{i=1}^{n} \frac{1}{2}\left(C_{i}+C_{i+1}\right)\left(x_{i+1}-x_{i}\right)\right\}
$$

where $\mathrm{n}$ is the total number of SIMS measurements, $\mathrm{C}_{\mathrm{i}}$ and $\mathrm{x}_{\mathrm{i}}$ are the SIMS concentration and the location of each data point, and $\mathrm{L}$ is the length of the crystal. Using Eq. (5), one gets

$\mathrm{C}_{0, \text { sIMs }}=3.5 \times 10^{18} \mathrm{~cm}^{-3}$. The discrepancy between $\mathrm{C}_{0, \text { sIMS }}=3.5 \times 10^{18} \mathrm{~cm}^{-3}$ and $C_{0}=2.1 \cdot 10^{18} \mathrm{~cm}^{-3}$ is attributed to the lack of calibration standards at the time of the SIMS measurements.

Based on the Eq. (5) and the SIMS data, the first to freeze section of the crystal should have $\mathrm{C}_{S}(0)=\mathrm{kC}_{0 \text {, sIMS }}=10.7 \cdot 10^{18} \mathrm{~cm}^{-3}$. The highest measured dopant concentration, $0.45 \mathrm{~mm}$ from the undoped seed is $\mathrm{C}(0.45 \mathrm{~mm})=7.71 \cdot 10^{18} \mathrm{~cm}^{-3}$. Considering the high concentration gradient and the size of the SIMS spot $(400 \mu \mathrm{m} \times 400 \mu \mathrm{m})$, the measured concentration appears reasonable.

The total length of the SUBSA 10 crystal without the seed is $36.02 \mathrm{~mm}$. In SUBSA 10, after $\approx 1 \mathrm{~cm}$ long initial transient (corresponding to $\chi \approx 0.7$ ), the distribution of $\mathrm{Zn}$ reached a steady state concentration. By assuming that the steady state concentration is equal to $\mathrm{C}_{0 \text {, sims }}=3.5 \times 10^{18} \mathrm{~cm}^{-3}$ and by fitting the Eq. (1) to the data, one gets the value of the diffusion coefficient of $\mathrm{Zn}$ in InSb, D $=1.2 \times 10^{-4} \mathrm{~cm}^{2} / \mathrm{s}$ (see full line in Fig. 4).

For SUBSA 08 and 09, during seeding, $2 \mathrm{~mm}$ of the undoped seed were melted, reducing the $\mathrm{Zn}$ concentration in the melt close to the seed (Fig. 5 and 6 respectively). Furthermore, the baffle, did not fully withdraw into its initial position (i.e. did not translate as planed, see Fig. 7). Therefore, the profiles obtained in SUBSA 08 and 09 experiments are difficult to interpret. Still, one can appreciate that during the first several millimeters of growth, the concentration does not exhibit a sharp initial transient, and that the initial concentration in the solid is close or below the 
average concentration, although $\mathrm{k}=2.9$. This lack of the initial transient could be of interest in some practical applications where initial transient is undesirable.

Six of the seven InSb space-grown crystals (four Te-doped [11] and SUBSA 08 and SUBSA 09) show an intimate contact with the crucible wall, attributed to the action of the carbon spring, pushing the melt towards the crucible, and thus preventing dewetting. However, the external surface of the SUBSA 10 crystal clearly shows evidence of partial dewetting. The the first $\sim 15 \mathrm{~mm}$ of the crystal (close to the seed, see Fig. 3) has a smooth shiny surface typical of crystals grown in an intimate contact with the silica wall. Yet, after approximately $20 \mathrm{~mm}$ of growth (see Fig. 8 a), the shiny regions typical of good melt-crucible contact, alternate with areas with ridges and valleys, typical of partial dewetting. In the last to freeze section of the crystal, strong surface striations can be seen (Fig. 8b) that can be related to dewetting with a discontinuous movement of the melt-crucible contact-line, as explained by Schweizer [15]. Figure 8 c) shows a particularly rough section, typical of full de-wetting, similar to the morphology reported by Witt et al. [1] .

According to the theory of dewetting [16], a meniscus exists between the crucible wall and the solid-liquid interface. For $\sim 4000 \mathrm{~N} / \mathrm{m}^{2}$ exerted by the carbon spring, the Young-Laplace Equation gives a radius of curvature for the meniscus of $\mathrm{r} \sim 300 \mu \mathrm{m}$. With such a small meniscus radius, only a very high contact angle between InSb melt and the silica ampoule (a few degrees below $180^{\circ}$ ), could have enabled dewetting to occur. Since a contact angle of close to $180^{\circ}$ has never been reported for InSb and silica, it is likely that the carbon spring and piston did not work properly towards the end of growth, yielding pressure significantly lower than $4000 \mathrm{~N} / \mathrm{m}^{2}$.

Dewetting should cause convective interference with segregation driven by gradients in surface tension. Therefore, the diffusion controlled initial transient in the first $15 \mathrm{~mm}$ of growth, is consistent with the shiny crystal surface, typical of the intimate contact between the melt and the crucible, providing zero-velocity at the wall (i.e. no-slip boundary condition). Furthermore, the deviation form diffusion controlled steady-state segregation of Zn (Fig.4) after approximately $22 \mathrm{~mm}$ of growth, is consistent with thermocapillary convection due to the free liquid meniscus associated with the partial dewetting documented in Fig. $3 \mathrm{c}$ ) and Fig. 8. A simple order of magnitude analysis [17] gives the velocity of the melt due to thermocapillary convection: 


$$
u=-\frac{d \sigma}{d T} \frac{d T}{d z} \frac{H}{\rho v},
$$

where $\mathrm{u}$ is the melt velocity $[\mathrm{cm} / \mathrm{s}], \rho=6.48\left[\mathrm{~g} / \mathrm{cm}^{3}\right]$ is melt density and $v=0.0033\left[\mathrm{~cm}^{2} / \mathrm{s}\right]$ is melt kinematic viscosity [5, 18]. Based on [5], the gradient in surface tension caused by temperature is $d \sigma / d T \sim 0.08\left[\mathrm{~g} / \mathrm{s}^{2}-\mathrm{K}\right],[5]$. The temperature gradient along the meniscus is estimated to be, $\mathrm{dT} / \mathrm{dz}$ is $\sim 50[\mathrm{~K} / \mathrm{cm}]$. Assuming the meniscus length scale to be $\mathrm{H} \sim 0.01 \mathrm{~cm}$. Eq. (6) gives the melt velocity at the meniscus surface of $\sim 2.3 \mathrm{~cm} / \mathrm{s}$, which could have a significant impact on the diffusive transport. Yet, it is not clear that the flow driven by the surface tension gradient, along a $\sim 100 \mu \mathrm{m}$ meniscus, could develop significant convection in the bulk melt, to disturb the segregation process (even though the meniscus is located next to the solid-liquid interface).

\section{Conclusions}

Three $\mathrm{Zn}$-doped InSb crystals $(\mathrm{k}=2.9)$ have been grown under microgravity conditions within the SUBSA investigation conducted at the International Space Station. To prevent bubble formation and dewetting a static pressure of $\sim 4000 \mathrm{~N} / \mathrm{m}^{2}$ was imposed on the melt, using a piston driven by a carbon spring. In two experiments (SUBSA 08 and SUBSA 09) a carbon baffle was used [12] to minimize the possible effects of the residual micro-acceleration. Both experiments show absence of the initial transient, which is difficult to interpret, but could be useful for certain applications. The third crystal (SUBSA 10), grown without the baffle, shows a good agreement with the Smith et al. equation [6], predicting a particularly short diffusioncontrolled initial transient, typical for systems with $\mathrm{k}>1$, which, to our knowledge has not been experimentally demonstrated so far. Furthermore, the appearance of partial deweting after about $20 \mathrm{~mm}$ of growth coincides with the departure from steady-state diffusion controlled segregation towards the end of growth. An order of magnitude analysis shows that the thermocapillary convection on the meniscus surface leads to the melt velocity of $\sim 2 \mathrm{~cm} / \mathrm{s}$. The partial deweting in SUBSA 10 is attributed to a mechanical problem, which may have prevented the carbon spring from applying sufficient static pressure on the melt. 


\section{Acknowledgements}

The SUBSA Microgravity Science Glovebox investigation was sponsored by the National Aeronautics and Space Administration. The authors wish to acknowledge the continuous help and support from: Linda Jeter, the SUBSA Project Manager. The authors also wish to acknowledge the continuous engineering support from Paul Luz NASA/Marshall Space Flight Center, Timothy R. Knowles, Energy Sciences Laboratories, Inc. and Gene Nelson of University of Alabama in Huntsville (UAH). The SUBSA furnace was designed by Reggie Spivey of TecMasters Inc., and built by Guy Smith of UAH. The SUBSA experiments at ISS were conducted by Peggy Whitson, Payload Specialist. The French author acknowledges funding from the CNES and ESA (Program MAP-CdTe).

\section{References}

[1] A.F. Witt, H.C.Gatos, M.Lichtensteiger, M.C. Lavine and C.J. Herman, J. Electrochem. Soc. 122 (1975) 276-283.

[2] C. Stelian, T. Duffar J. Crystal Growth 275 (2005) 175-184

[3] O.Pätzold, B.Fischer, A.Cröll, Cryst. Res. Technol. 37 (2002) 1058-1065

[4] Nishinaga T., Ge P., Huo C., He J., Nakamura T., J. Crystal Growth 174 (1997) 96-100

[5] Duffar, T., Potard, C., and Dusserre, P., J. Crystal Growth 92 (1988) 467-478.

[6] Smith, V.G., Tiller, W.A., and Rutter, J.W., Canadian Journal of Physics 33, (1955). p. 723745.

[7] V.S. Zemskov, I.L. Shul'pina, A.N. Titkov, I.N. Belokurova, N.B. Guseva, and V.I. Safarov, Sov Phys Solid State 21 (1979) 576.

[8] Zemskov, V.S., Raukhman, M. R., Barmin, I. V., Senchenkov, A. S., Shul'pina, I. L., Sorokin, L. M., Fizika i Khimiya Obrabotki Materialov, 1983(5): p. 56-65.

[9] Zemskov, V.S., Raukhman, M. R., and Shalimov, V. P., Poverkhnost. Rentgenovskie, Sinkhrotronnye i neitronnye issledovaniya, 2002. 2: p. 38-43.

[10] D.C. Gillies, S.L. Lehoczky, F.R. Szofran, D.A. Watring, H.A. Alexander and G.A. Jerman, J. Crystal Growth 174 (1997) 101-107. 
[11] A. G. Ostrogorsky, C. Marin, A.Churilov, Martin Volz, W.A. Bonner, T. Duffar, "Reproducible Tedoped InSb Experiments at the International Space Station”, J. Crystal Growth 310 (2007) 364371.

[12] A. G. Ostrogorsky, C. Marin, A. Churilov, Martin Volz, W.A. Bonner, R. A. Spivey and G. Smith, $\boldsymbol{A I A A}$ 2003-1309, 41th AIAA Aerospace Sciences Meeting \&Exhibit, January 2003/Reno, Nevada

[13] Carslaw \& Jaeger, "Conduction of Heat in Solids", Oxford Univ. Press, Second Edition (1986)

[14] O.W. Memelink. Philips Res. Rep. 11 (1956), 183-189.

[15] M. Schweizer, M.P. Volz, S. D. Cobb, L. Vujisic, S. Motakef, J. Szoke, F. R. Szofran, J. Crystal Growth 237-239 (2002) 2107-2111

[16] T. Duffar, P. Boiton, P. Dusserre, J. Abadie, J. Crystal Growth 179 (1997) 397-409

[17] D. Camel, P. Tison, J.J. Favier, Acta Astronautica 13 (1986) 723-726

[18] G Muller, A. G. Ostrogorsky, Handbook of Crystal Growth, 1993 - North Holland 


\section{Figure Captions}

Fig. 1 Initial transient in dopant concentration, $C_{S}(\chi, k) / C_{0}$, as a function of dimensionless distance and of the equilibrium segregation coefficient, calculated using: Eq. (1) (dashed lines with symbols, for $\mathrm{k}=0.1,0.3,0.5,1.5$ and 2.9) and Eq. (6), (full line).

Fig. 2 a) Transparent SUBSA ampoule made out of fused silica; b) $9 \mathrm{~mm}$ diameter graphite spring use to push the piston, to apply static pressure to the melt. c) piston and baffle, polished and CVD coated with a $2 \mu \mathrm{m}$ thick layer of hard pyrocarbon,

Fig. 3 a) and c) the "D" shaped sections and b) $1 \mathrm{~mm}$ thick plate cut from the central section of SUBSA 10. The "D" shaped sections in c) shows surface morphology typical of dewetting.

Fig. 4 Dopant segregation in SUBSA 10 crystal grown at $6.67 \mathrm{~mm} / \mathrm{hr}$ without a baffle. The mass of the InSb charge and $\mathrm{Zn}$ dopant are $22.974 \mathrm{~g}$ and $0.0009 \mathrm{~g}$ respectively, giving $\mathrm{C}_{0}$ $=2.083 \times 10^{18} \mathrm{~cm}^{-3}$ Less than $0.1 \mathrm{~mm}$ of the seed was melted. The circles and squares are two sets of SIMS data obtained without a calibration standard. Equation (1) fitted to the data, gives $\mathrm{D}=1.2 \times 10^{-4} \mathrm{~cm}^{2} / \mathrm{s}$.

Fig.5 Dopant segregation in SUBSA 09 crystal grown at $5 \mathrm{~mm} / \mathrm{hr}$ without a baffle. $2 \mathrm{~mm}$ of the seed was melted. The mass of the $\mathrm{Zn}$ is $0.0009 \mathrm{~g}$ giving $\mathrm{C}_{0}=2.02 \times 10^{18} \mathrm{~cm}^{-3}$ The squares are SIMS data.

Fig.6 Dopant segregation in SUBSA 08 crystal grown at $5 \mathrm{~mm} / \mathrm{hr}$ without a baffle. $2 \mathrm{~mm}$ of the seed was melted. The mass of the $\mathrm{Zn}$ is $0.0009 \mathrm{~g}$ giving $\mathrm{C}_{0}=2.02 \times 10^{18} \mathrm{~cm}^{-3}$ The squares are SIMS data.

Fig. 7 Computed tomagraphy scans of Zn-doped crystals: top SUBSA 10, middle SUBSA 08, Bottom SUBSA 09. The baffle in SUBSA 08 is $1 \mathrm{~mm}$ short of its initial position. The baffle in SUBSA 09 is about $2 \mathrm{~cm}$ from the seed.

Fig.8 Pictures of the SUBSA 10 external surface showing (a) partial dewetting; (b) surface striations that can be related to dewetting with a discontinuous movement of the meltcrucible contact-line; c) full dewetting. 
6. Figure(s)

Click here to download high resolution image

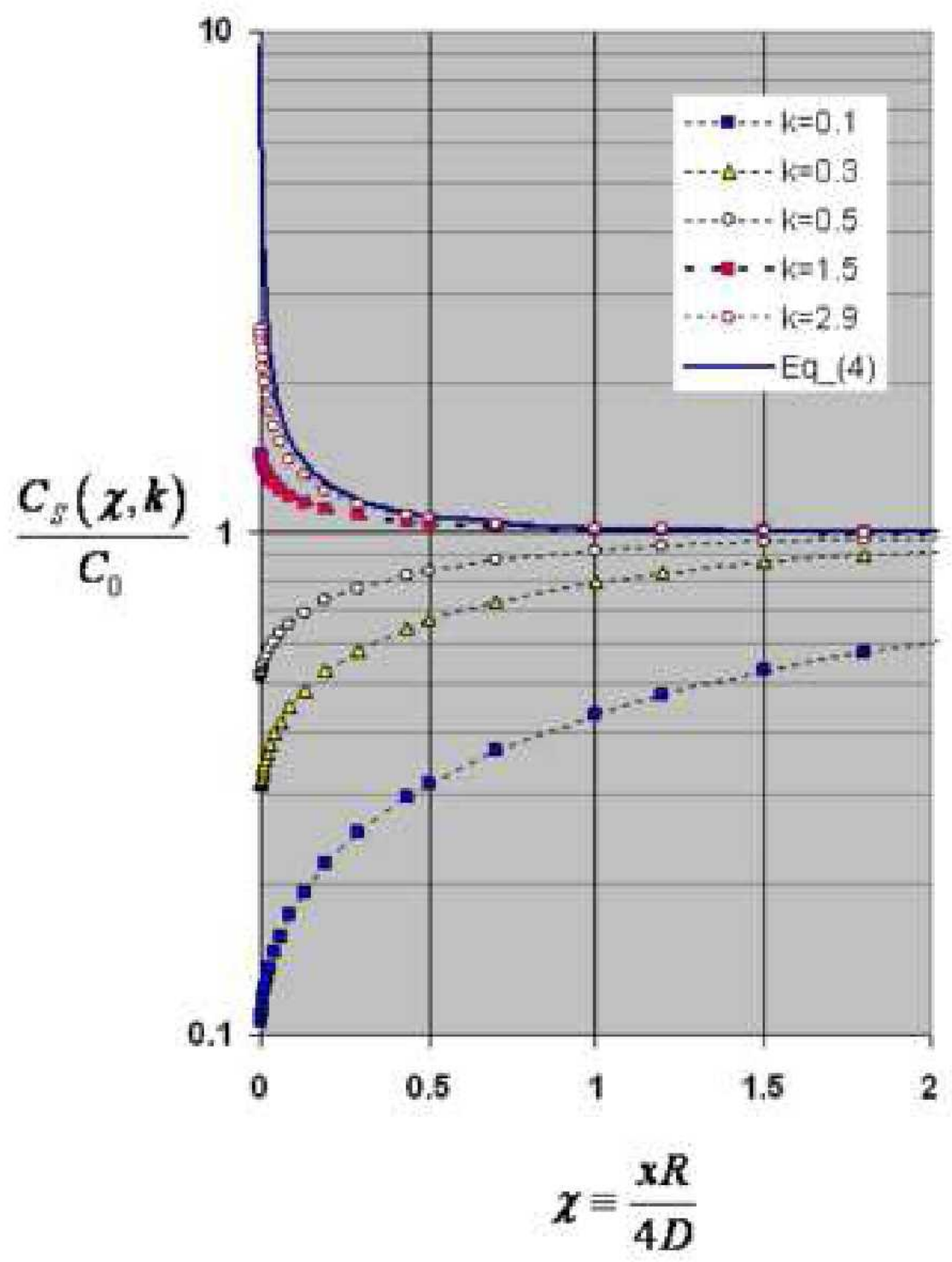

Fig 1 
6. Figure(s)
Click here to download high resolution image

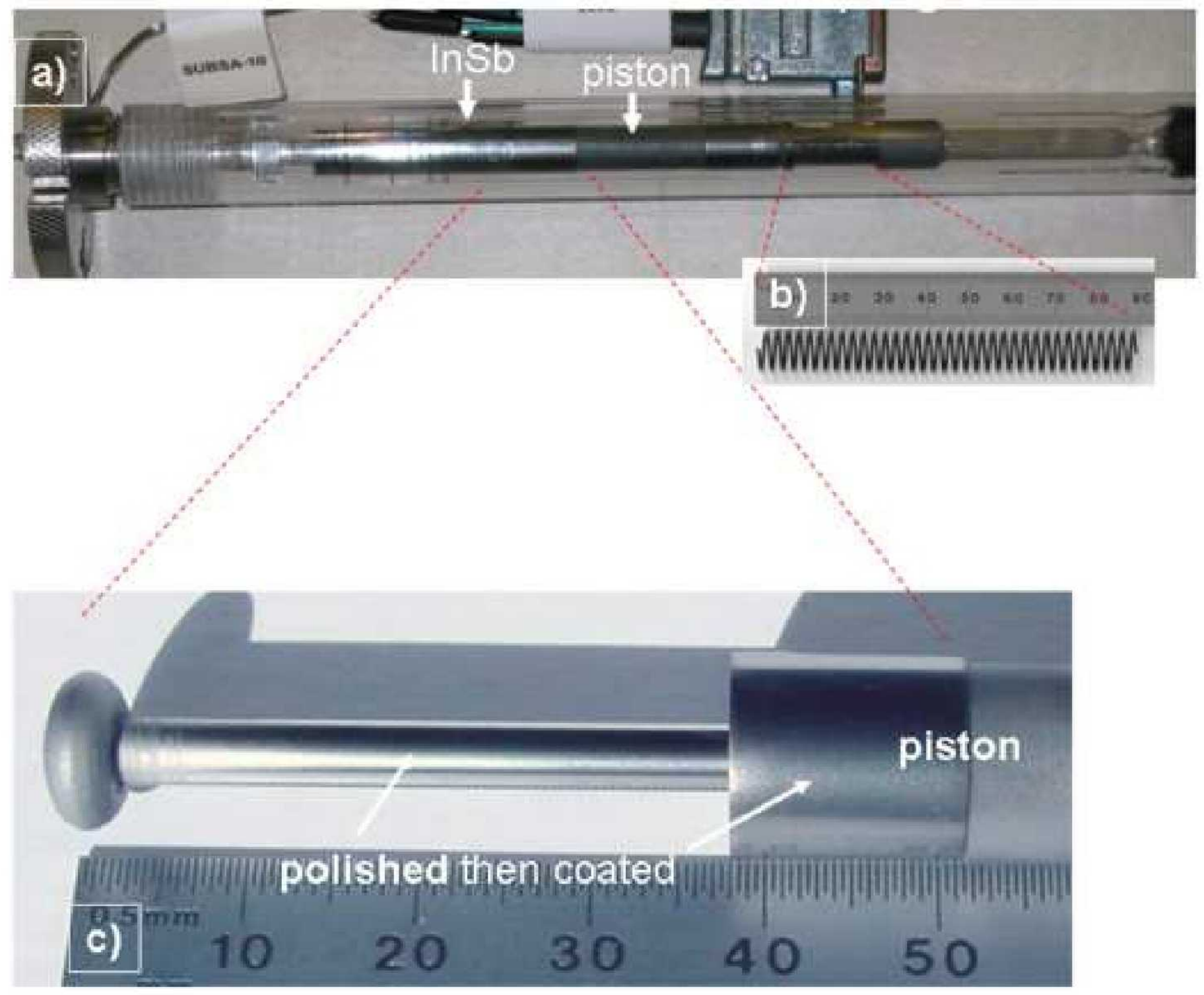

Fig 2 

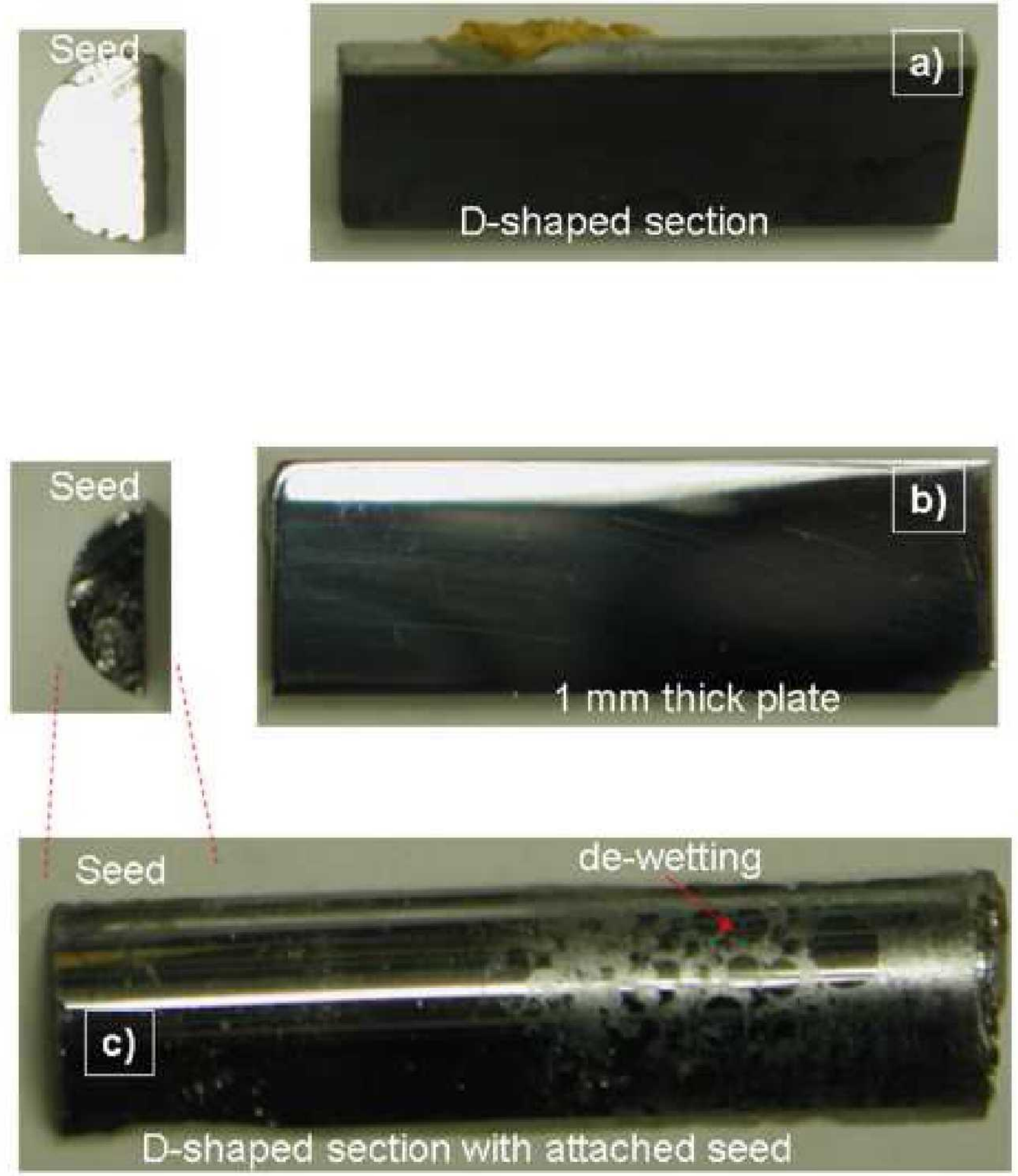

Fig 3 
6. Figure(s)

Click here to download high resolution image

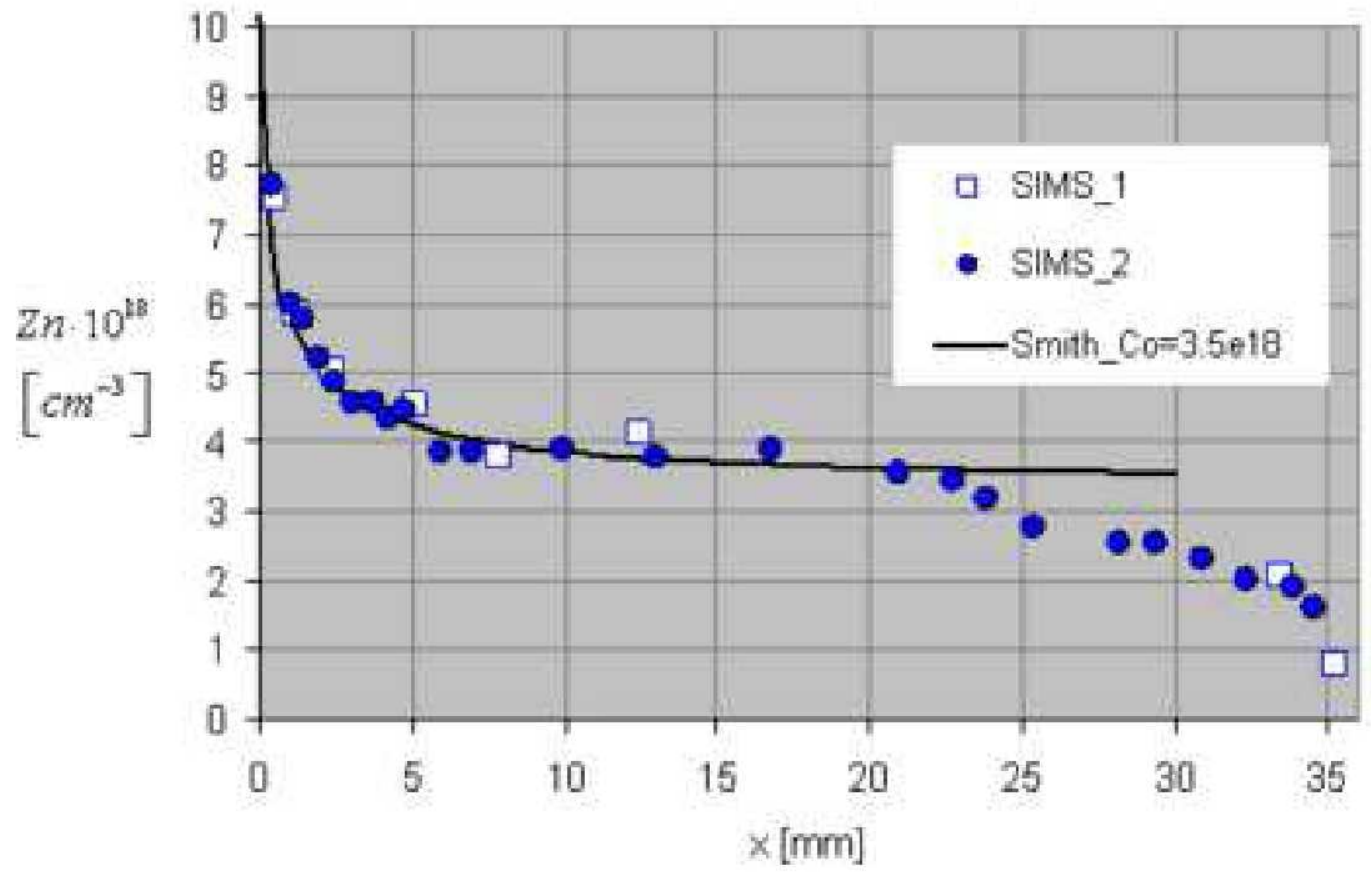

Fig 4 
6. Figure(s)

Click here to download high resolution image

SUBSA 9 Zn-doped baffle

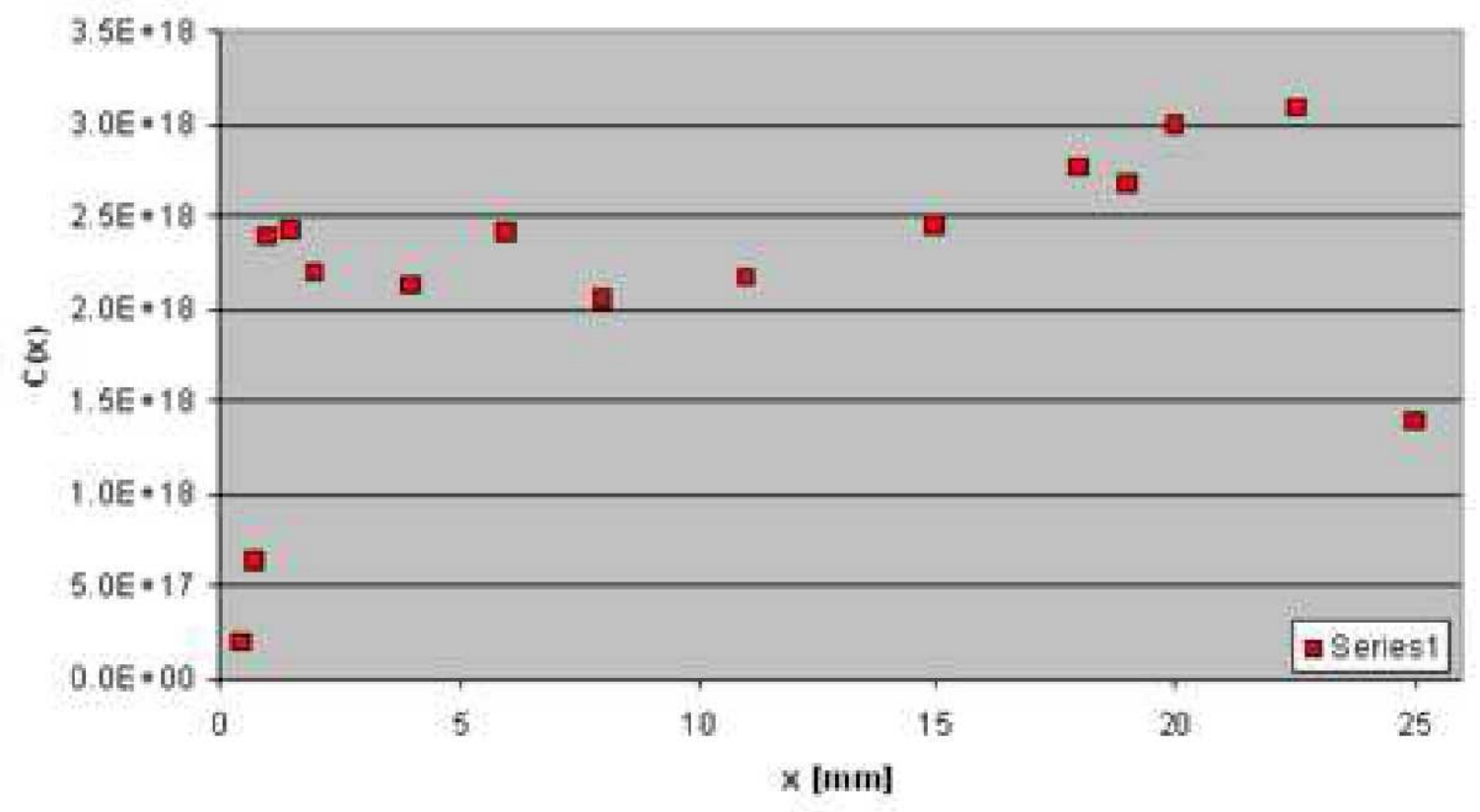

Fig 5 
6. Figure(s)

Click here to download high resolution image

SUBSA 8 Zn-doped; baffle

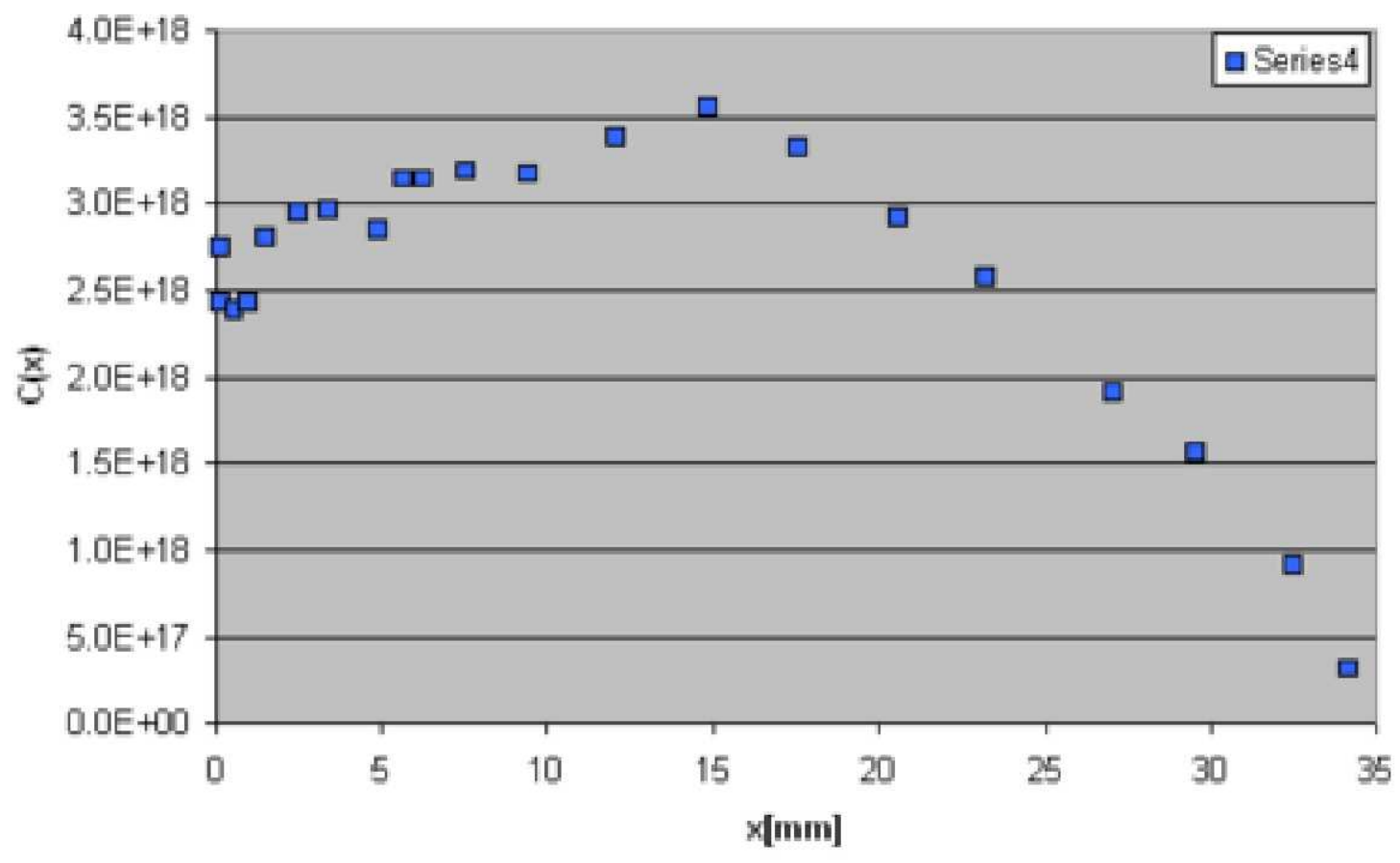

Fig 6 
6. Figure(s)

Click here to download high resolution image
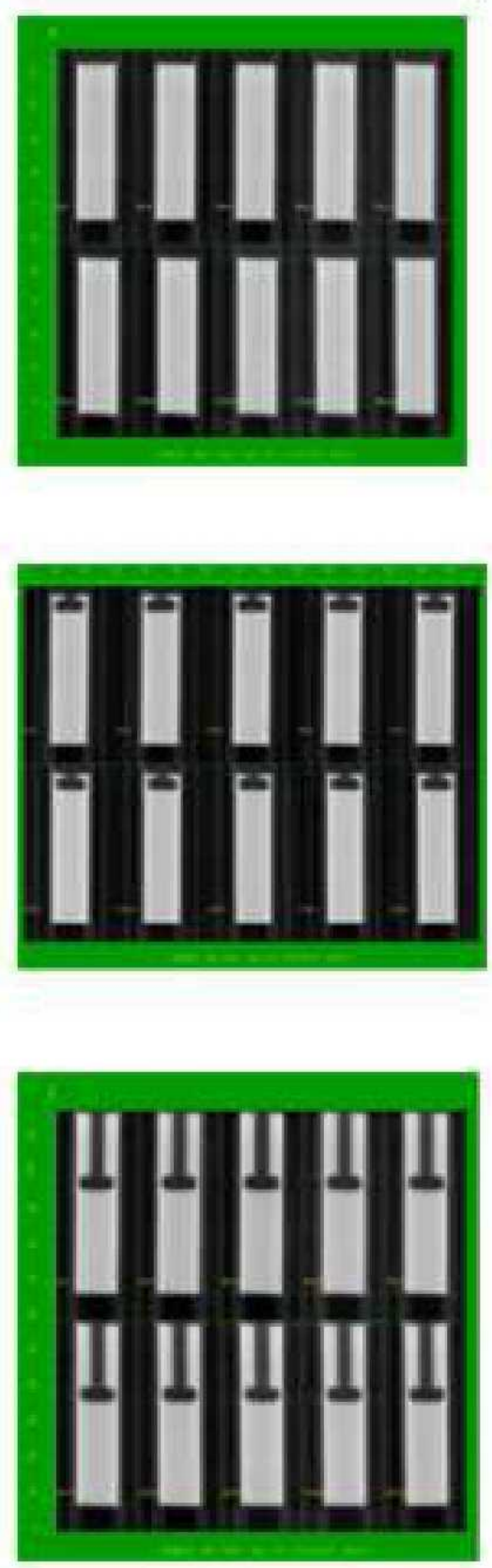

Figure 7. 
6. Figure(s)

Click here to download high resolution image
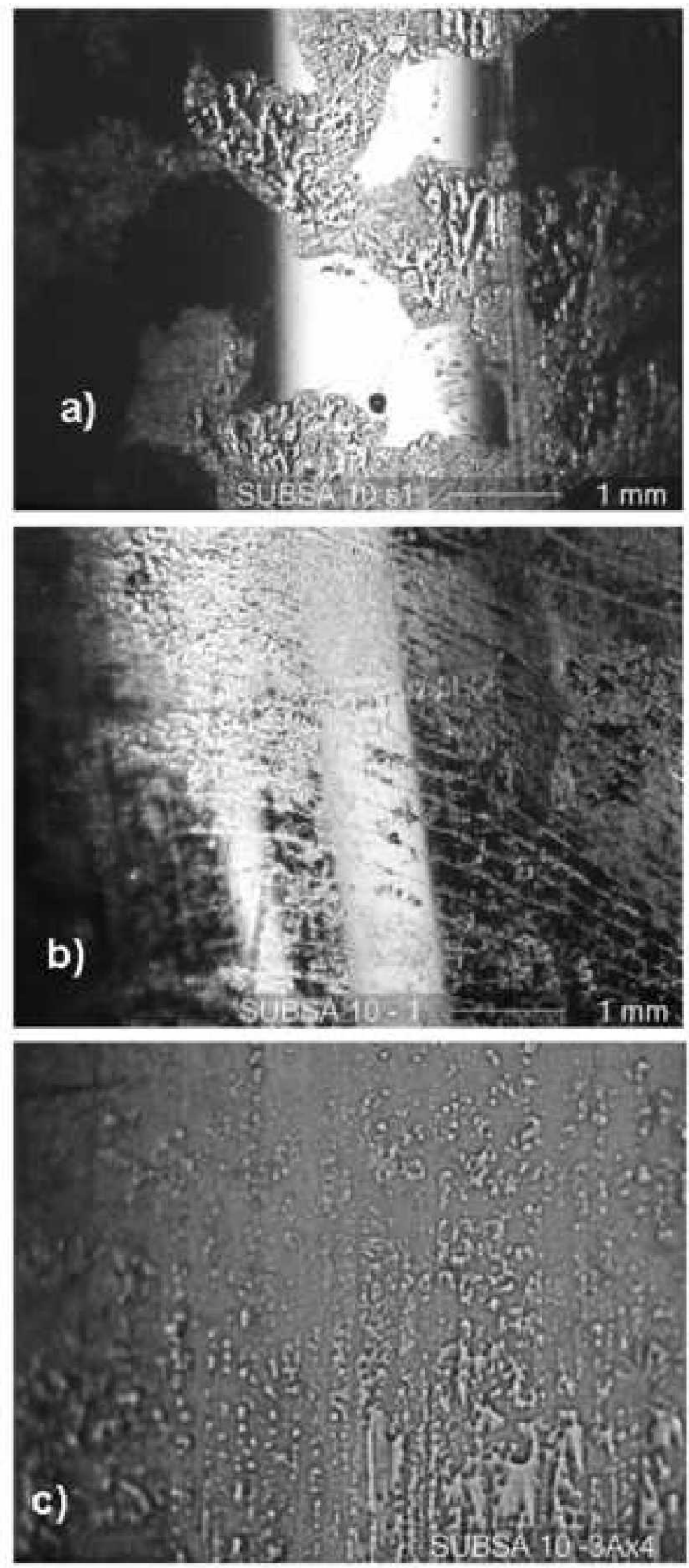

Fig

8 